\title{
SURGICAL CLOSURE OF LARGE OROANTRAL FISTULA BY MODIFIED SANDWICH TECHNIQUE AND PEDICLED BUCCAL FAT PAD : (A CLINICAL STUDY)
}

\author{
Abdel Aziz Baiomy Abdullah Baiomy* and Hossam El-Din Mohamed Ali**
}

\begin{abstract}
Aim: The aim of this study was to evaluate the efficacy of modified sandwich technique and pedicled buccal fat pad (PBFP) to achieve both hard and soft tissue closure of large OAF.

Patients and methods: The bony defects of five patients complaining from large OAF were grafted by modified sandwich technique comprising Fisiograft bone substitute between absorbable haemostat membrane (surgicel) and guided tissue regeneration membrane. Then the sandwich graft was covered by buccal bad fat graft. The patients were followed up clinically after 1, 2, 4 and 12 weeks postoperatively. Radiographic evaluation by OPG and nuclear bone scan was performed immediately, 3 , and 6 month postoperatively.
\end{abstract}

Results: Successful closure of the OAF was achieved in all cases without reported recurrence of the OAF or regurgitation of fluids from the nose. Radiographically, after 3rd month, bony defects of the OAF showed partial radioopecity which completed at 6th month interval. Bone scan measurements showed highly statistically significant increase in the bone activity values at grafted site after 3rd month postoperatively. While activity index (AI) values at 6 month interval decreased to return toward lower level than baseline values.

Conclusion: The results clearly concluded that this technique with PBFP is successful in achieving proper anatomical closure of large OAF in terms of both hard and soft tissues.

\section{INTRODUCTION}

Oroantral communication (OAC) with progressive formation of oroantral fistula (OAF) is one of the clinical complications encountered by oral and maxillofacial surgeons. There are several causes for OAC occurrence such as maxillary posterior teeth extraction, surgical removal of maxillary pathological lesions, and trauma ${ }^{(1,2)}$.
When the OAF has been present for 3-4 weeks, or when its diameter is greater than $5 \mathrm{~mm}$ chance of spontaneous healing is less possible. If oroantral opening remains untreated, the escape of fluids, other mouth contents and oral bacteria into the maxillary sinus will be occurred leading to the patients experience chronic maxillary sinusitis ${ }^{(3,4)}$.

Various techniques and treatment modalities

* Lecturer of Oral and Maxillofacial Surgery, Faculty of Dental Medicine (Assiut), Al-Azhar University 
have been described for the closure of OAF, such as buccal advancement flap, palatal flap and related modifications, buccal pad fat grafts, and distant flaps $^{(1,5)}$. The buccal fat pad (BFP) is one of them which is a lobulated mass of fatty tissue surrounded by a slight capsule, located inside the masticatory spaces $^{(6,7)}$. The easy mobilization, its excellent blood supply, the proximity of the BFP for the recipient area, and minimal donor-site morbidity are clear advantages of the BFP as a graft material ${ }^{(8-10)}$.

However most of these techniques depend on soft tissue closure only without grafting the bony defect. This is in opposite side for the rising demand for implant rehabilitation ${ }^{(1)}$. Therefore, numerous bone grafts have been proposed for closure of OAF such as autogenous bone grafts, allografts, xenografts, alloplastic materials ${ }^{(11-14)}$. Although all these modalities of treatment have been successful, each of them has its own limitation or shortfall.

Sandwich technique is one of the techniques which are used for OAC/OAF closure with the advantage of concurrent bone tissue regeneration in the OAC/OAF site. Sandwich technique comprising hydroxyapatite crystals within a collagen network sheet has not only led to a proper anatomical closure, but also aided in the reformation of lost bone structure. The reconstructed bony tissue regenerated from this technique will also be able to receive an endosseous implant ${ }^{(15)}$. Drawbacks of this technique are that it is less suitable for $\mathrm{OAC} /$ OAF larger than $10 \mathrm{~mm}^{2}$ and the fact that sandwich graft need buccal advancement flap to cover graft. Buccal advancement flap have several drawbacks such as reduction of the buccal sulcus depth, thin thickness, and postoperative pain ${ }^{(1,16)}$.

Several studies concluded that absorbable haemostat containing oxidized regenerative cellulose can be used to manage perforated maxillary sinus membranes because of its excellent physical and biological properties. It is easily adaptable to the perforated membranes, cheaper than other repairing materials, able to act as a loose matrix with the blood clot in the sinus, assist bone formation in the repair of palatal clefts, and to assist bone remodeling guided tissue regeneration ${ }^{(17,18)}$.

Because of several advantages of PBFP and absorbable haemostat containing oxidized regenerative cellulose, aim of this study was to benefit from these advantages in closure oroantral fistula. This study was a trial to evaluate the effectiveness of modified sandwich technique comprising bone substitute between absorbable haemostat membrane containing oxidized regenerative cellulose and guided tissue regeneration membrane covered by PBFP in the closure of large OAF.

\section{PATIENTS AND METHODS}

\section{Patients selection:}

The study was carried on 5 patients ( 2 female and 3male) aged 28-55year. They were selected from Oral and Maxillofacial Surgery Outpatient Clinic, Faculty of Dentistry, Al-Azhar University, Assiut branch. Informed consent was obtained from all patients before any study procedures were performed. The clinical study extended from 2012 till 2016 year (table 1). All the patients were free from any local or systemic condition that may interfere with healing process.

\section{Preoperative examination}

\section{1- Clinical examination}

Patients might come complaining of regurgitation of fluids from the nose on the affected side, inability to blow out the cheeks and alternation in the vocal resonance. Patients were examined clinically to assess the OAF by propping it with a blunt prop or by nose blowing test (fig.1.a).

\section{2- Radiographic examination}

A panoramic view $\mathrm{X}$-ray was required to view the OAF and intra-sinus pathology or any foreign bodies. 


\section{Preoperative preparation:}

All the patients were prepared preoperatively with irrigation of sinus with normal saline for 7 days and no evidence of maxillary sinusitis was ensured before surgery. Amoxicillin, Metronidazole, decongestant nasal drops and steam inhalation were given for 7 days preoperatively.

\section{Materials:}

- Fisiograft : (GHIMAS, S.P.A. Italy) is a polylactic / polyglycolic copolymer bone substitute. Fisiograft is available in 3 different forms; sponge, gel, and powder. The gel form was used in this study.

- Surgicel : (Johnson \& Johnson, Ascot, UK) it is absorbable haemostat containing oxidised regenerative, 2 in x 3 in size

- GTR: (Bio-Gide®, Geistlich, Wolhusen, Switzerland) it is resorbable collagen membrane

\section{Sandwich technique for closure of oroantral fistula}

- After administration of local anesthesia, a circular incision with a 2-mm margin was made around the OAF and the epithelial tract and pathological lesions within the opening was completely excised (figs1. a \&b \& c).

- Two divergent cuts were made from each end of the circular incision extending into the vestibule. The trapezoidal buccal mucoperiosteal flap was reflected from the alveolar process and the lateral wall of the maxilla.

- Bony defect was curetted by bone curette to removal any necrotic tissue. Then the mesiodistal and bucco- lingual dimensions of the bony defect were measured by digital vernier (table 1).

- Surgicel membrane was press fit into bony defect of maxillary sinus. Then Fisograft gel was applied on surgicel membrane and sandwiched between it and GTR membrane (figs.1.d \& e).

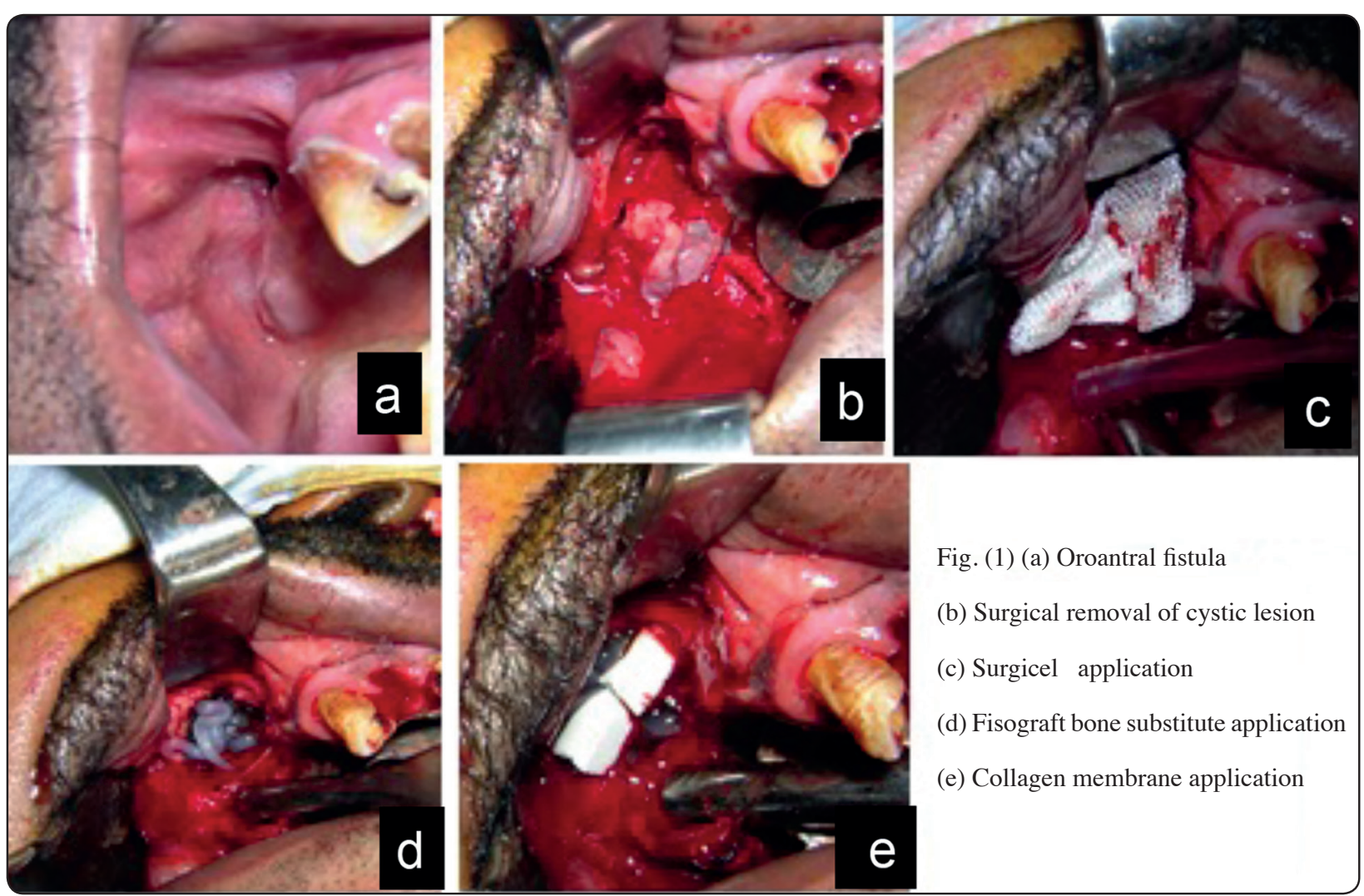


TABLE (1) Demographic variables, etiology ,size

\begin{tabular}{|c|c|c|c|}
\hline $\begin{array}{c}\text { Serial no. of } \\
\text { patients }\end{array}$ & $\begin{array}{c}\text { Age (years) / } \\
\text { Gender }\end{array}$ & Etiology & $\begin{array}{c}\text { Size } \\
\left(\mathbf{m m}^{\mathbf{2}}\right)\end{array}$ \\
\hline $\mathbf{1}$ & 28 years/ female & Extraction & 39.5 \\
\hline $\mathbf{2}$ & 37 years/male & Extraction & 43.0 \\
\hline $\mathbf{3}$ & 55 years/male & Cyst & 51.0 \\
\hline $\mathbf{4}$ & 41 years/female & Cyst & 52.4 \\
\hline $\mathbf{5}$ & 50 years/male & Cyst & 36.0 \\
\hline Mean & $41.5 \pm 13.5$ & & $44.34 \pm 8.2$ \\
\hline
\end{tabular}

PBFP technique for covering of modified sandwich graft

- The buccal pad of fat was exposed through a $1 \mathrm{~cm}$ long vertical incision in the reflected periosteum posterior to the zygomatic buttress.

- The buccal pad of fat was gently advanced into the bony defect above sandwich graft and secured to the palatal mucosa without tension, with 4-0 vicryl sutures (fig 2.a).

- Finally, the mucoperiosteal flap was replaced in its original position and sutured (figs. 2 b \& c)

- Prefabricated protective splint was placed postoperatively for 10 days to stabilize flaps and grafts (fig.2 d).

- Routine postoperative instructions including; application of ice compresses to minimize edema, soft diet, maintaining good oral hygiene, using betadine mouth wash were instructed to the patients.

- The patients were instructed to avoid strenuous physical activities (nose blowing, sneezing, using suction tubes for drinking, vigorous sports) that might raise the pressure within the paranasal sinuses. The sutures were removed after 10 days from surgery.

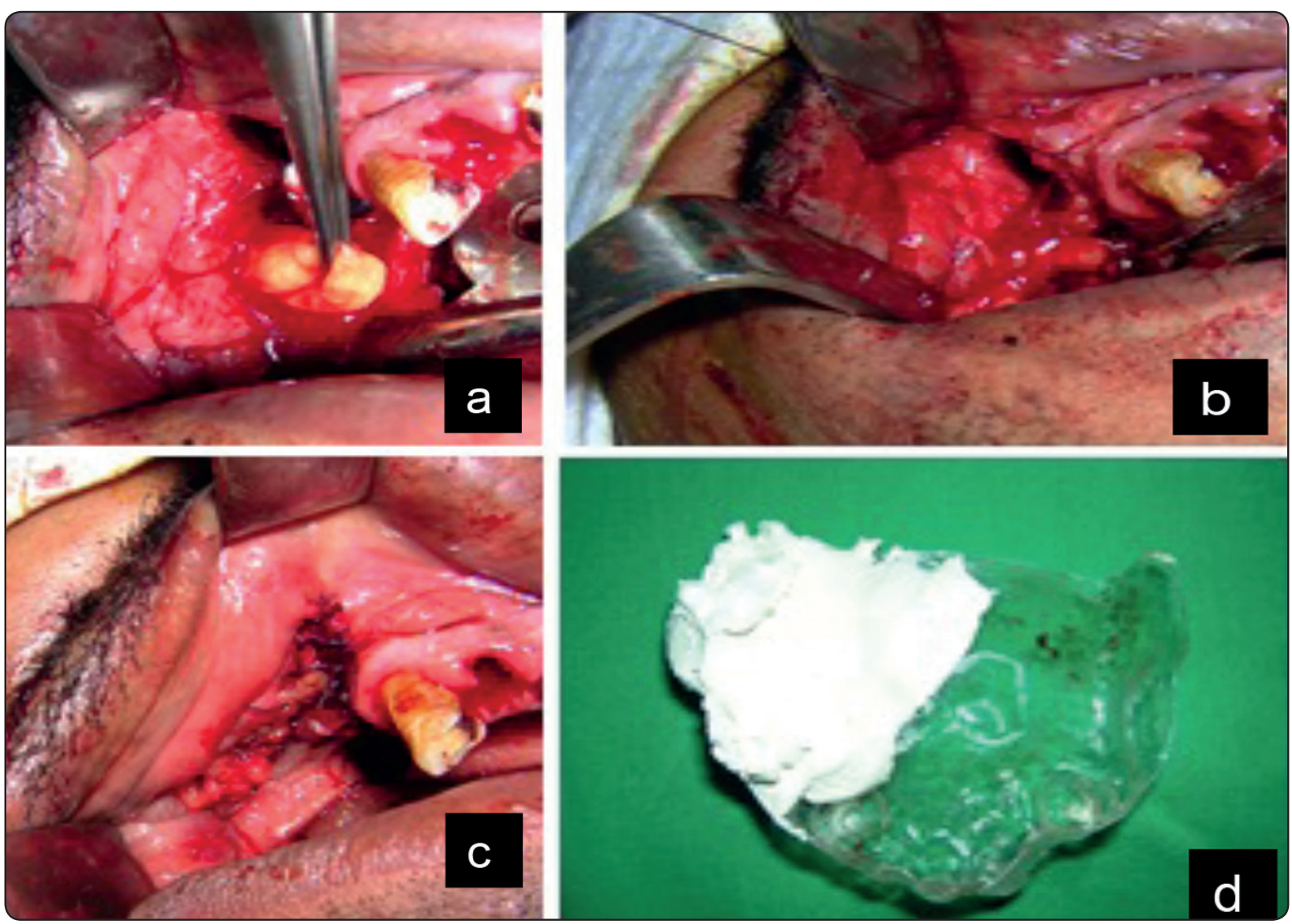

Fig. (2) (a, b) PBFP application (c) Buccal flap suturing to palatal mucosa (d) Palatal stent with periodontal dressing. 


\section{Postoperative follow up and evaluation:}

\section{Clinical follow up}

The patients were examined after 1, 2, 4, and 12 weeks to inspect:

1. Healing of the surgical wound.

2. Local allergic or inflammatory reaction.

3. Relapse of the oroantral communication.

4. Any signs or symptoms of maxillary sinusitis.

5. Any undesired results that occurred.

\section{Radiographic follow up:}

Panoramic radiographs were taken immediately after surgery,3, and 6 month postoperatively to evaluate quality of bone formation at OAF region after grafting procedure .While Scintigraphic evaluation by single photon emission computerized tomography (SPECT) was performed to quantize bone regeneration through an activity index (AI) calculation at site of modified sandwich graft .

An activity index (AI) was calculated as follows equation: $\mathrm{AI}=$ Average counts (pixel) at operation site / average counts (pixel) in skull

\section{Statical analysis:}

Data of SPECT evaluation were be collected and tabulated for statistical analysis. The statistical analysis was done using Statistical Package for Social Sciences (SPSS) Version 15.0 statistical analysis software at level of significant $5 \%$.

\section{RESULTS}

\section{Clinical observations}

Successful closure of the OAF was achieved in all cases. None of the cases reported recurrence of the $\mathrm{OAF}$ or any postoperative undesired complications such as wound dehiscence, infection, rejection of (fig. 3.a).

\section{Quality of bone formation}

By the end of 3 months there was an evidence of bone formation in all patients and in two from them bony radioopecity at OAF defect was almost similar to the adjacent normal bone. By the end of 6 months follow up all patients showed that bony trabaculae at OAF region was indistinguishable with the adjacent bone (fig. 3.b).

\section{Quantity of bone formation:}

Measurements of SPECT evaluation showed that bone activity index values of all patients passed through three phases during the study. First phase (immediately after surgery) showed a slow rise of the AI, suggesting increased bone formation and inflammatory responses compared with normal adjacent bone. In second phase (at 3 month interval)
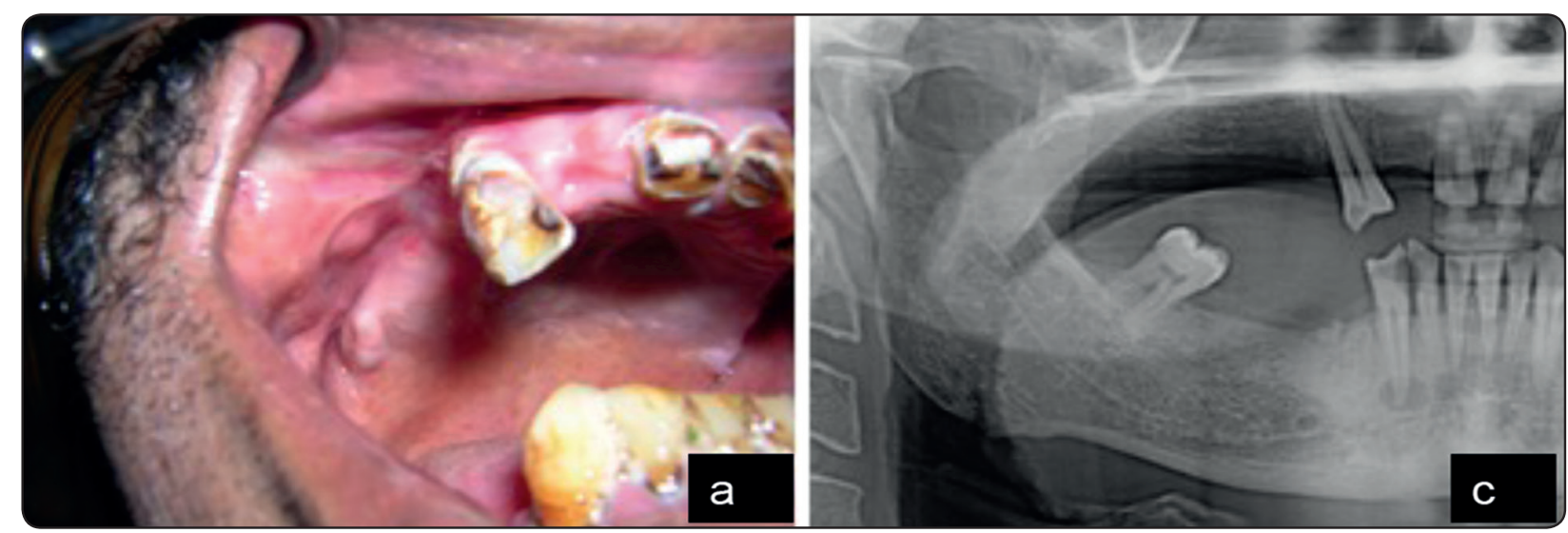

Fig. (3) (a) Postoperative clinical photography for wound healing (b) Postoperative panoramic view showing bone formation 
activity index values reached to maximal values than other phases. While AI values at 6 month interval (phase three) decreased to return toward lower level than baseline values and became in the same level of adjacent normal bone. AI values at $3^{\text {rd }}$ months had highly significant difference than AI values of other intervals of evaluation (table 2) .

TABLE (2) Means and standard deviation of postoperative bone activity index values.

\begin{tabular}{|c|c|c|c|c|c|}
\hline Time & $\begin{array}{c}\text { Min } \\
(\%)\end{array}$ & $\begin{array}{c}\text { Max } \\
(\%)\end{array}$ & $\begin{array}{c}\text { Mean } \\
(\%)\end{array}$ & S.D & P \\
\hline $\begin{array}{c}\text { Postoperative } \\
\text { Immediately }\end{array}$ & 2.8 & 3.1 & 3.0 & \pm 0.12 & \multirow{2}{*}{0.001} \\
\cline { 1 - 4 } After $3^{\text {rd }}$ month & 3.6 & 4.4 & 4.0 & \pm 0.41 & \multirow{2}{*}{} \\
\cline { 1 - 4 }${\text { After } 6^{\text {th }} \text { month }}^{1.7}$ & 2.1 & 1.9 & \pm 0.24 & \\
\hline
\end{tabular}

\section{DISCUSSION}

Oroantral fistula is pathologic communication between oral cavity and maxillary sinus, usually localised between antrum and buccal vestibule. Persisting OAF always causes chronic maxillary sinusitis ${ }^{(1)}$. So many causes can lead to fistulas which can involve the nasal and antral cavities or even both. They may result from various entities such as pathological ones or secondary to removal of tumors or maxillary cysts. However, the main cause of oroantral fistula is the extraction of a maxillary molar or premolar ${ }^{(10)}$.

Several techniques have been utilized for OAF closure, such as the use of mucoperiosteal flap techniques (vestibular, palatine, lingual or combined), bone grafts or buccal fat pad grafts $(1,19)$. These techniques have main shortfall that is only soft tissue closure is achieved; hence the need of complex hard tissue (bone) grafting when endosseous implant is considered ${ }^{(15)}$.

The present study describes a new technique for closure of the OAF, in which both hard (bone) and soft tissue closure was achieved for prosthetic rehabilitation purpose. The technique used a GTR membrane and surgical included Fisograft material between them for closure of large OAF defect then covered by PBFP to support bony graft and ensure soft tissue closure.

In our study, successful closure of the OAF was achieved in all cases. This can be explained by that grafting the bony defect by suitable bone graft not only reduces the bone resorption expected, but also it protects and supports the soft tissue closure as discussed by Haas et al ${ }^{(20)}$.

Fisograft (PLA/PGA copolymer) gel form was used as bone grafting in the present study to benefit from its osteopromotive capability and rapid biological degradation. This matched with histological results of Tawfik et al (14) and Zaffie et $\mathrm{al}^{(21)}$ that reffered to capability of Fisiograft in prompting bone regeneration, with or without the use of a bone substitute and Fisiograft shows potential bone stimulation function, which may be labelled as osteopromotive capability.

Mean size of the OAF defect in the present study was $44.34 \pm 8.2 \mathrm{~mm}^{2}$. All patients had a favourable healing course and the wounds were epithelialized 2-3 weeks after surgery. This may be explained by several advantages of PBFP which was used to support sandwich graft and encourage soft tissue healing . This in the same side with Colella et al ${ }^{(8)}$ and Akerzoul et al ${ }^{(10)}$ conclusions.

All patients showed a highly statistically significant radiologic evidence of bone formation at 3 , 6 month interval. Quantitave SPECT was used in the present study to evaluate activity of bone formation at grafted site, which was matched with Khan et al (22) conclusions. They concluded that SPECT offers a simple, reproducible, objective and physiologic approach to studying the osseointegration process that occurs after placement of endosseous implant. 
According to Ogunsalu ${ }^{(15)}$ this method can also be utilized for the measurement of osteoblastic activity index following the sandwich technique.

AI values of SPECT evaluation demonstrated that osteoblastic activity index reach to the highest level at 3month interval then return to normal level at 6 month interval. This proved that complete bone formation occurred. This in the same side with histological results of Tawfik et al ${ }^{(14)}$ study that pointed out biodegradation of Fisograft takes up of 3 months.

One of the limitations of the study is the relatively small number of cases, and also this study lacks control. Despite the limitations, results of the present study proved that combined use of modified sandwich technique together with PBFP was a very simple, easy and helpful technique in closure of large OAFs. The technique not only improved the bone healing and reduced vertical alveolar bone loss, but it also increased the success rate of closure of the OAFs.

\section{REFERENCE}

1. Visscher SH, van Minnen B, Bos RRM. Closure of oroantral communications: a review of the literature. $\mathrm{J}$ Oral Maxillofac Surg 2010;68:1384-91

2. Yilmaz T, Suslu AE, Gursel B. Treatment of oroantral fistula: experience with 27 cases. Am J Otolaryngol 2003;24:221-3.

3. Martensson G. Operative method in fistulas to the maxillary sinus. Acta Otolaryngol 1957;48:253-4.

4. Ehrl PA. OAC, epicritical study of 175 patients, with special concern to the secondary operative closure. Int $\mathrm{J}$ Oral Surg 1980;9:351-5.

5. Hanazawa Y, Itoh K, Mabashi T, Sato K. Closure of oroantral communications using a pedicled buccal fat pad graft. J Oral Maxillofac Surg 1995;53:771-6.

6. Martin-Granizo R, Naval L, Costas A, et al: Use of buccal fat pad to repair intraoral defects: Review of 30 cases. Br J Oral Maxillofac Surg 1997;35:81-6.
7. El Hakim IE, El Fakharany AM: The use of the pedicled buccal fat pad (BFP) and palatal rotating flaps in closure of oroantral communication and palatal defects. J Laryngol Otol 1999; 113:834-9.

8. Colella G, Tartaro G, Giudice A. The buccal fat pad in oral reconstruction. Br J Plast Surg 2004; 57:326-9.

9. Adeyemo WL, Ladeinde AL, Ogunlewe MO, Bamgbose BO. The use of buccal fat pad in oral reconstruction - a review. Niger Postgrad Med J 2004; 11:207-11.

10. Akerzoul N, Chbicheb S, El wady W. Surgical Closure of Oro-Antral Fistula (OAF) using Buccal Fat Pad Graft: A Case Report and Review of Literature . Int J Oral Health Med Res 2015 ; VOL 2 :32-5.

11. Betz RR. Limitations of autograft and allograft: new synthetic solutions. Orthopedics 2002;25:561-70.

12. Basl_e MF, Grizon F, Pascaretti C, Lesourd M, Chappard D. Shape and orientation of osteoblast-like cells (Saos2) are influenced by collagen fibers in xenogenic bone biomaterial. J Biomed Mater Res 1998;40:350-7.

13. Sheridan MH, Shea LD, Peters MC, Mooney DJ. Bioabsorbable polymer scaffolds for tissue engineering capable of sustained growth factor delivery. J Control Release 2000;64:91-102.

14. Tawfik MA, Gadallah HT, El Hawary YM. Role of polylactic polyglycolic copolymer (Fisigraft) in bone regeneration: an experimental study. Egypt Dent J 2005; 51:31- 6 .

15. Ogunsalu C. A new surgical management for oro-antral communication: The resorbable guided tissue regeneration membrane--bone substitute sandwich technique. West Indian Med J 2005; 54:261-3.

16. Hariram, Pal US, Mohammad S, Singh RK, Singh G, Malkunje LR. Buccal fat pad versus sandwich graft for treatment of oroantral defects: A comparison. Natl J Maxillofac Surg.2010; Vol 1: 7- .

17. Kim YK, Choe GY, Yun PY. Management of perforated sinus membrane using absorbable haemostat and fibrin adhesive for sinus lift procedure. Asian J Oral Maxillofac Surg. 2008; 20:129-134.

18. Galgut PN. Oxidized cellulose mesh used as a biodegradable barrier membrane in the technique of guided tissue regeneration. A case report. J Periodontol. 1990; 61:766-8. 
19. Kraut RA, Smith RV. Team approach for closure of oroantral and oronasal fistule. Atlas Oral Maxillofac Surg Clin North Am 2000; 8: 55-75.

20. Haas R,Watzak G, Baron M, Tepper G, Mailath G, Watzek GA. A preliminary study of monocortical bone grafts for oroantral fistula closure. Oral Surg Oral Med Oral Pathol Oral Radiol Endod 2003; 96:263-6.
21. Zaffe D, Leghissa GC, Pradelli J, Botticelli AR. Histological study on sinus lift grafting by Fisiograft and Bio-Oss. J Mater Sci Mater Med. 2005 Sep;16(9):789-93.

22. Khan O,Archibald A, Thompson E. The role of quantitative single photo emission computerized tomography (SPECT) in the osseous integration process of dental implants. Oral Surg Oral Med Oral Pathol 2000; 90: 228-32. 